\title{
Observations of the trade wind wakes of Kauai and Oahu
}

\author{
Yang Yang, ${ }^{1,2}$ Jian $\mathrm{Ma}^{3}$ and Shang-Ping $\mathrm{Xie}^{1,3}$ \\ Received 20 August 2007; revised 13 December 2007; accepted 17 January 2008; published 22 February 2008.
}

[1] The Hawaiian islands of Kauai and Oahu stand in the path of the east-northeasterly trade winds, creating wakes in the lee. For the first time, the structure of the wakes and their diurnal cycle were observed on a cruise during $18-20$ December 2006. The dynamic wakes, characterized by reduced trades, extend about $1 \mathrm{~km}$ in height with strong wind shear at the top. Thermal forcing of these small islands also affects the wake circulations. Sea breezes develop in the afternoon turning the winds into westerly near the shore in the wakes. At night, land breezes advect cool air from the islands, creating a shallow cool layer between the sea surface and a capping inversion. The warming in the wake in the afternoon extends much deeper $(1.4 \mathrm{~km})$ than the cool layer $(0.5 \mathrm{~km})$ at night. The effect of diurnal changes on cloud formation in the wakes is discussed, and the sharp variations in wind velocity lee of the islands may affect ocean currents, waves and mixing. Citation: Yang, Y., J. Ma, and S.-P. Xie (2008), Observations of the trade wind wakes of Kauai and Oahu, Geophys. Res. Lett., 35, L04807, doi:10.1029/2007GL031742.

\section{Introduction}

[2] Volcanic mountains on the Hawaiian Islands significantly modulate the prevailing northeast trade winds, and the strong resultant wind curls drive steady currents [Xie et al., 2001; Sasaki and Nonaka, 2006] and eddies in the ocean [Calil et al., 2007] with important climatic and biological effects. Variations in stratification across island wakes modify the refractivity and evaporation duct height, thereby affecting radar signal propagation [Burk et al., 2003]. The island of Hawaii, the largest and tallest (maximum elevation at $4.2 \mathrm{~km}$ ) in the Hawaiian island chain, has been studied extensively [e.g., Nickerson and Dias, 1981; Smith and Grubišić, 1993; Yang and Chen, 2003]. Both observational and modeling studies show a wake circulation west of the island of Hawaii with lee vortices and a westerly return flow.

[3] Kauai and Oahu are much smaller in size but satellite observations and modeling studies indicate that they exert important effects on the circulations in the lee [Burk et al., 2003; Lane et al., 2006; Porter et al., 2007; Y. Yang et al., The thermal wake of Kauai Island: Satellite observations and numerical simulations, submitted to Journal of Climate, 2008]. Island-induced circulations and turbulence are pos-

\footnotetext{
${ }^{1}$ International Pacific Research Center, School of Ocean and Earth Science and Technology, University of Hawaii at Manoa, Honolulu, Hawaii, USA.

${ }^{2}$ Now at National Institute of Water and Atmosphere, Wellington, New Zealand.

${ }^{3}$ Department of Meteorology, School of Ocean and Earth Science and Technology, University of Hawaii at Manoa, Honolulu, Hawaii, USA.
}

Copyright 2008 by the American Geophysical Union. 0094-8276/08/2007GL031742\$05.00 sible factors for the crash of the solar-powered aircraft Helios lee of Kauai on 26 June 2003 [Lane et al., 2006; Porter et al., 2007]. Froude number $(\mathrm{Fr}=\mathrm{U} / \mathrm{Nh})$ is an important parameter determining the dynamical regimes of island wakes, where $U$ is the background wind speed, $N$ the Brunt-Väisälä frequency, and $h$ the mountain height [Smith, 1989; Smolarkiewicz and Rotunno, 1989; Bauer et al., 2000]. One important result of Smolarkiewicz and Rotunno [1989] is that a pair of counter-rotating vortices develop downstream of the mountain without friction, but surface friction can generate vorticity in the boundary layer and be carried to the interior of the fluid by boundary layer separation. For typical trade-wind conditions $\left(U=8 \mathrm{~m} \mathrm{~s}^{-1}\right.$, $N=0.008 \mathrm{~s}^{-1}$ ) upstream of Hawaii, $F r$ is 0.6 and 0.8 for Kauai and Oahu (1.6 and $1.2 \mathrm{~km}$ in maximum elevation), respectively. Theoretical and numerical studies [e.g., Smith, 1989] predict wakes without lee vortices and return flow lee of these two islands, a dynamical regime different from that of the much taller island of Hawaii that features a reversed flow. While consistent with idealized studies of stratified flow over isolated obstacles, these numerical simulation results have not been verified by observations lee of Kauai and Oahu.

[4] With a resolution of $25 \mathrm{~km}$ and contamination by land emission near the coast, satellite scatterometers [Xie et al., 2001] are inadequate to observe the Kauai and Oahu wakes, islands small in size $(\sim 50 \mathrm{~km}$; Figure 1). Satellite cloud observations are limited in utility to cloudy regions and incapable of detecting variations in the surface mixed layer ( $\sim 500 \mathrm{~m}$ deep) where the wake circulation is expected to be strong, especially lee of short islands. Here we report results from a cruise designed to observe the structures of the Kauai and Oahu wakes. The cruise took place during 18-20 December 2006 on board the R/V Kilo Moana as an education initiative, designed and run by graduate students. Continuous surface ( $\sim 10 \mathrm{~m} \mathrm{MSL})$ meteorological observations were recorded by using the ship-board MET suite. See http://www.soest.hawaii.edu/UMC/KiloMoana.htm for the details of instrumentation. Air pressure, temperature, and relative humidity are recorded every second, and winds every 2 seconds at an accuracy of $1 \mathrm{~m} \mathrm{~s}^{-1}$ for speed and 1 degree for direction. All variables shown here are averaged for 1 minute. Vertical soundings of the atmosphere using GPS-sondes were also conducted. To our knowledge, this is the first time that the wakes of these islands have been mapped from observations. The objective of this paper is to study the dynamically induced wakes of Kauai and Oahu, and their diurnal variations with these observations.

[5] During the cruise, the soundings at Lihue on the windward coast of Kauai showed weak to normal tradewind conditions (Table 1). For the cruise on the lee side of Kauai (Oahu), the averaged low-level wind speed is 7.5$8.0(6.4-7.6) \mathrm{m} \mathrm{s}^{-1}$ with an averaged wind direction of $58-$ $71(57-63)$ degree from north. The trade-wind inversion is 


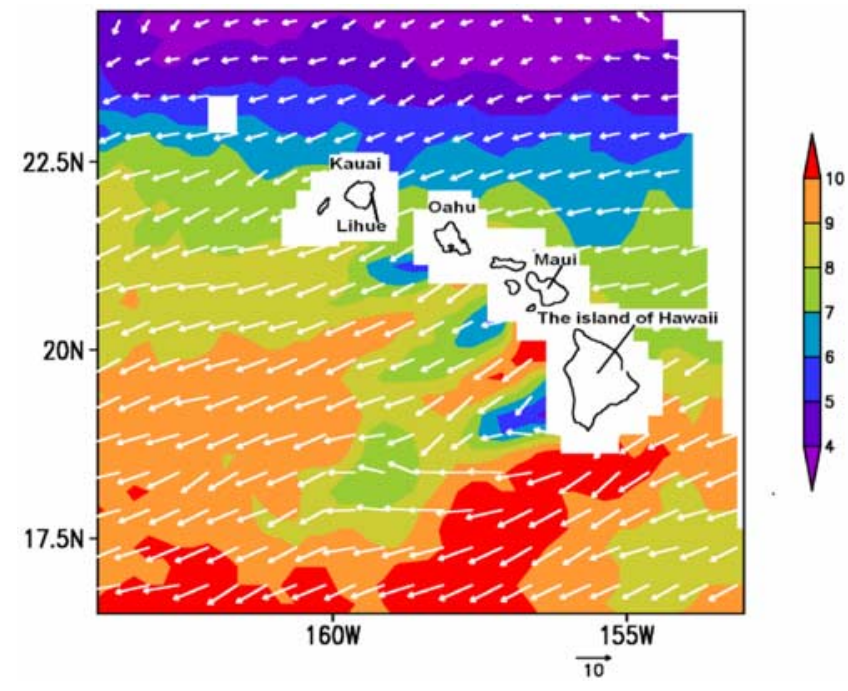

Figure 1. QuikScat wind vectors around 0640 HST, 19 December 2006. The color shading shows the wind speed $\left(\mathrm{m} \mathrm{s}^{-1}\right)$.

$1900-2100 \mathrm{~m}$ for Kauai cruise but $1600-1920 \mathrm{~m}$ for Oahu cruise. The latter is lower than the typical trade-wind inversion height $(2000 \mathrm{~m})$ but still much higher than the mountaintop of Oahu. The small variations of the tradewind strength, direction and inversion height during the cruise are assumed to have minor effects on the wake circulations.

\section{Dynamic Wakes}

[6] Figure 1 shows the QuikSCAT wind velocity on the morning of 19 December 2006. The trades are clearly slowed down by the major Hawaiian islands. The influence of Kauai is unclear in QuikSCAT as the sea between it and Niihau is masked out to avoid contamination from land microwave emission. The cruise captures the wakes of both Kauai and Oahu, and the sharp shear lines between the wake and the accelerated trades $\left(\sim 10 \mathrm{~m} \mathrm{~s}^{-1}\right)$ on the flanks (Figure 2). Across the shear lines, wind speed commonly changes by $10 \mathrm{~m} \mathrm{~s}^{-1}$ within $5-10$ minutes, equivalent to a distance of $2-5 \mathrm{~km}$. The cross-stream scale of the wake is about $50 \mathrm{~km}$, similar to the size of the islands. The downstream extension of the wake is at least $40 \mathrm{~km}$ based on the cruise data but appears to be greater than $100 \mathrm{~km}$ lee of Oahu in QuikSCAT observations (Figure 1). While the winds outside the wakes are steady and strong, the winds in the wakes are variable in both speed and direction and display clear diurnal variations, which will be discussed in the next section in detail. The wakes of reduced winds and strong shear lines on the flanks are robust features observed throughout the cruise.
[7] Figure 3 shows the wind profiles from 7 soundings launched from the ship (positions shown in Figure 2). Lee of Kauai (Figure 3a), sounding 2 is outside the wake and shows strong low-level winds $\left(10-15 \mathrm{~m} \mathrm{~s}^{-1}\right)$ while winds are weak below $600-700 \mathrm{~m}$ in the wake (soundings 1,3 and 4). Similar deceleration of low-level winds is observed in the Oahu wake (soundings 6 and 7; Figure 3b; due to temporary equipment problem, the data below $200 \mathrm{~m}$ of sounding 7 were missing), with strong and vertically uniform winds outside the wake (sounding 5). The upper boundary of the Oahu wake is estimated to be about 1200 $\mathrm{m}$ from sounding 6 .

[8] Winds in the wake show irregular vertical variations in strength and direction, indicative of turbulence. Large vertical wind shears are observed at the upper boundary of the wake (800-1200 $\mathrm{m}$ in height) and could be a source of turbulence. Indeed the bulk Richardson number reaches a vertical minimum of about 0.05 in this zone of high vertical shear in the wake (soundings 1, 3, 4, 6, and 7), as compared to a background value of $0.15-0.35$ from soundings 2 and 5 outside the wakes. High turbulence in the wake is broadly consistent with Lane et al.'s [2006] simulations of the Kauai wake.

\section{Diurnal Variations}

[9] Surface winds in the wake regions show significant diurnal variations in direction. In the Oahu wake, westerly sea breezes were observed in the afternoon, with the maximum wind speed of $7 \mathrm{~m} \mathrm{~s}^{-1}$ along the near-shore track, decaying further offshore (Figure 2a). The sea breezes have a cross-stream width of $20 \mathrm{~km}$, about the length scale of the Waianae range in west Oahu. Sounding 6, launched around 1410 HST, shows that the vertical extent of the westerly sea breezes over the nearby water is $400 \mathrm{~m}$ (Figure 3b), whereas the Lihue soundings show steady northeasterly trade winds at low levels during both day and night (Table 1). The westerly onshore winds during afternoon are present in long-term surface observations on the coast of west Oahu [Nguyen, 2006]. At night, the winds return to northeasterly at $\sim 5 \mathrm{~m} \mathrm{~s}^{-1}$. The nighttime wake appears to be broader in cross-stream extent than the daytime wake.

[10] Similar, albeit weaker, westerly sea breezes were observed in the lee of Kauai in the late morning (Figure 2b) and late afternoon, with wind speeds up to $4.5 \mathrm{~m} \mathrm{~s}^{-1}$ and vertical extent of $400 \mathrm{~m}$ (sounding 3 in Figure 3a). Land breezes on the lee side of Kauai were observed by nighttime soundings 1 and 4 inside the wake (Figure 3a). At 0130 HST, easterly land breezes $\left(0.5-3 \mathrm{~m} \mathrm{~s}^{-1}\right)$ were observed below $150 \mathrm{~m}$ (sounding 4 in Figure 3), a layer with cold temperatures capped by an inversion (Figure 4a). The land breezes were also observed by sounding 1 at $0630 \mathrm{HST}$ with a surface cold layer deepened to $450 \mathrm{~m}$. Soundings 1 and 4

Table 1. Averaged Wind Speed and Direction for Levels Between 1000 and $850 \mathrm{hPa}$, and the Trade-Wind Inversion Height From Lihue Soundings at the Windward Southeastern Coast of Kauai Island on 18, 19, and 20 December

\begin{tabular}{lccccc}
\hline & 0200HST 18 Dec & 1400HST 18 Dec & 0200HST 19 Dec & 1400HST 19 Dec & 0200HST 20 Dec \\
\hline Wind speed $\left(\mathrm{ms}^{-1}\right)$ & 7.5 & 8 & 7.6 & 6.4 & 7.4 \\
Wind direction (deg) & 65 & 71 & 58 & 57 & 63 \\
Inversion height (m) & 2100 & 1950 & 1900 & 1600 & 1920 \\
\hline
\end{tabular}



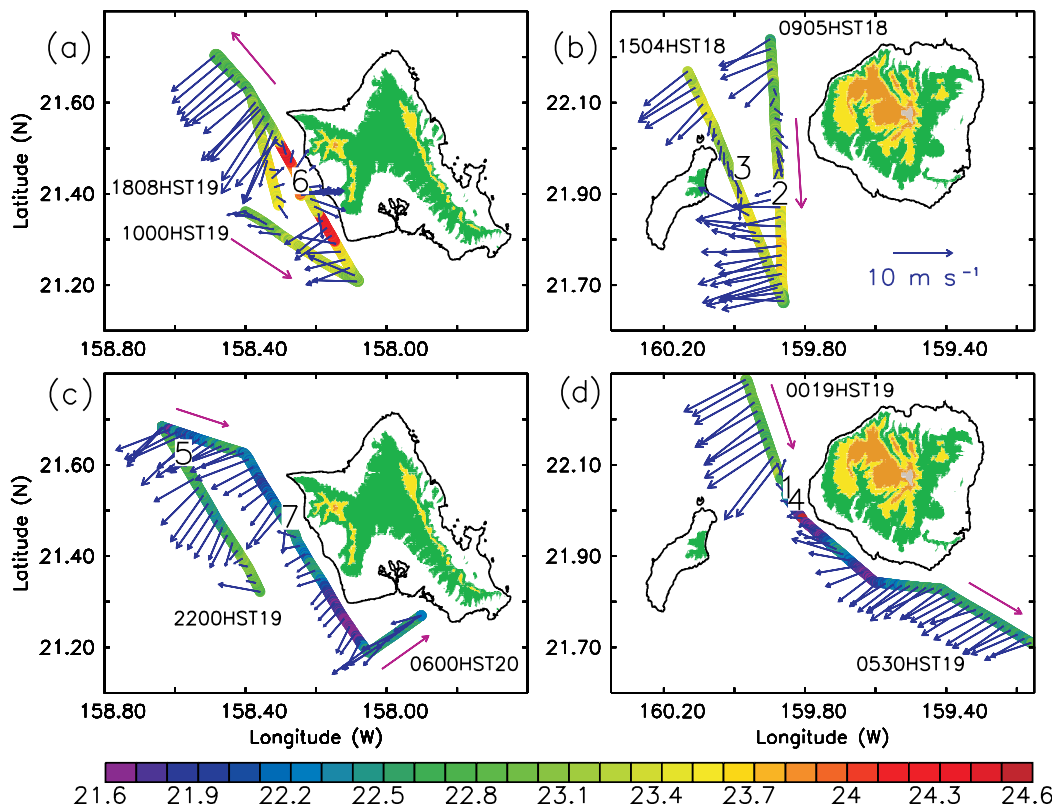

Figure 2. One-minute mean surface wind velocity (blue vectors in $\mathrm{m} \mathrm{s}^{-1}$ plotted at 6-minute intervals) and air temperature (color shading in ${ }^{\circ} \mathrm{C}$ ) along the ship tracks, in the lee of (a) Oahu and (b) Kauai during the (top) day and (bottom) night. The cruise direction is shown by the purple arrows with starting and ending times denoted in each panel. Positions of soundings 1-7 are overlaid. Island orography is mapped in color shade from $200 \mathrm{~m}$ with an interval of $400 \mathrm{~m}$.

were taken 19 hours apart but similar temperature and wind conditions at Lihue (Table 1) led us to assume that their differences are due mostly to diurnal variations rather than day-to-day variations.

[11] Pronounced diurnal variations in surface temperature were observed on the cruise, with the diurnal range up to 2.5 K lee of Oahu (Figure 2). On the near-shore track lee of

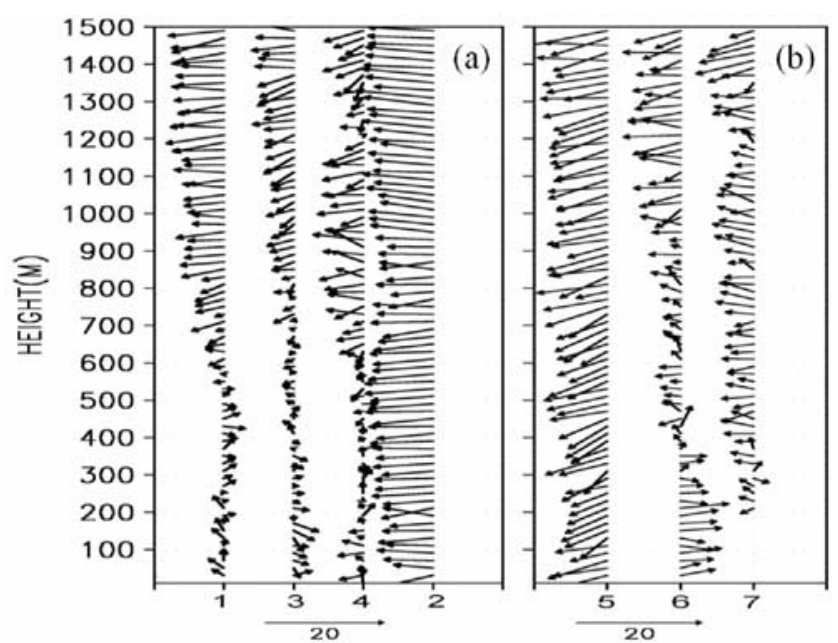

Figure 3. Wind $\left(\mathrm{m} \mathrm{s}^{-1}\right)$ profiles: (a) soundings $1,2,3$, and 4 launched at $0630,1110,1700$ HST on 18 December, and 0130 HST on 19 December 2006, respectively, lee of Kauai; and (b) soundings 5, 6, and 7 at 0010 HST, 20 December, 1410 HST 19 December, and 0245 HST 20 December 2006, respectively, lee of Oahu. Geographical positions of these soundings are shown in Figure 2 by numbers $1-7$.
Oahu, daytime temperature is $0.5-1 \mathrm{~K}$ higher than outside the wake, possibly due to the advection of warm air from the island (Figure 2a). On the northern flank of the wake, temperature is quite high despite onshore winds at the time of observations, suggesting that turbulent mixing from the warm West Oahu may be important there. Temperature is relatively low in the area with westerly sea breezes, which advect cool marine air toward the coast. At night, the leeside area cools, with temperature minima observed on the northern and southern edges of the Oahu wake (Figure 2c). The cool wake at night is very pronounced lee of Kauai with temperature $1 \mathrm{~K}$ lower than outside the wake (Figure $2 \mathrm{~d}$ ).
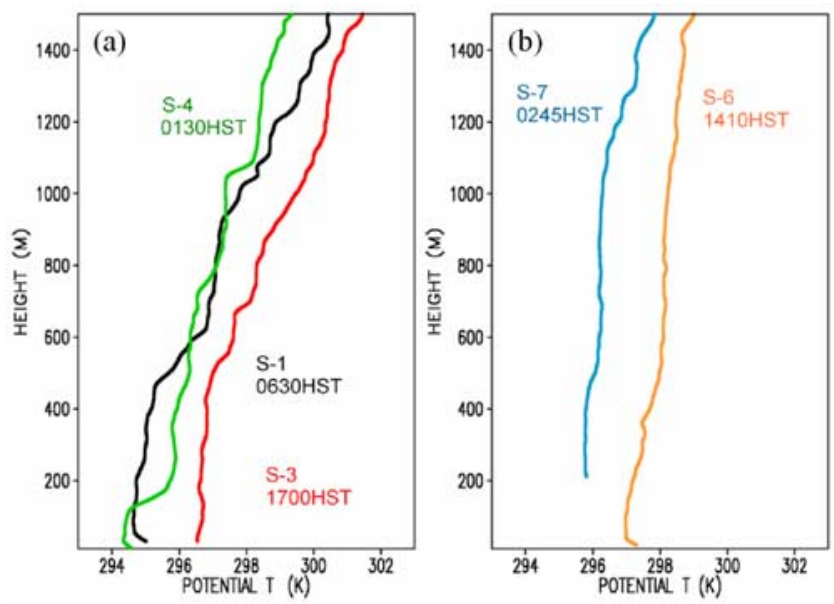

Figure 4. Potential temperature $(\mathrm{K})$ profiles: (a) soundings 1,3 , and 4 lee of Kauai; and (b) soundings 6 and 7 lee of Oahu. 
The cross-stream variations in temperature along the daytime tracks lee of Kauai are weak (Figure 2b). This is perhaps due to the tracking time and place. The daytime track close to Kauai was mainly in the morning with weak land surface heating, especially for its northern portion. The track farther away from Kauai (Figure 2b) was made in the afternoon. As surface air moves away from the island, the mixing may decrease the temperature difference between in and outside the wake.

[12] Diurnal changes in air temperature are well captured by the soundings in the wakes (Figure 4). In the Kauai wake, potential temperature in the late afternoon (sounding 3) is $2 \mathrm{~K}$ higher than in the early morning (sounding 1 ). The increase in day-time temperature in the wake reaches $1500 \mathrm{~m}$ above the sea surface. Sounding 4, taken just after mid-night, captures a cool surface layer capped by an inversion layer in 100-200 $\mathrm{m}$ above the surface. The cool surface layer is most likely a signature of the cold land breeze consistent with the easterly flow below the shallow inversion (Figure 3a). With continued land surface cooling, the cool layer gradually deepens from $200 \mathrm{~m}$ to $500 \mathrm{~m}$ at 0630 HST possibly through mixing (soundings 1 and 4). In the Oahu wake, the day-time warming extends from the surface to at least $1500 \mathrm{~m}$ high (Figure 4b).

\section{Summary and Discussion}

[13] We have mapped the island modulation of thermal and wind fields lee of Kauai and Oahu under northeast trade-wind conditions from a cruise. At $25-\mathrm{km}$ resolution, QuikSCAT data only show a slowdown of the trade winds lee of each of the major Hawaiian Islands. Continuous surface observations on the cruise capture sharp transitions between weak winds in the wake and the accelerated trades on the flanks. The wake bounded by shear lines to the north and south is a very robust feature lee of both Kauai and Oahu. Our soundings indicate that in the vertical, the wake is bounded by a layer of high wind shear at about $800-1200$ $\mathrm{m}$, above which the trade winds recover. These observational results confirm numerical simulations by Lane et al. [2006] for Kauai Island. The strong vertical windshear at the upper boundary of the wake may also be an important source of turbulence. Indeed, wind velocity in the wake shows large vertical variations in direction and speed, indicative of turbulence, in contrast to the robust lee vortices observed in the lee of the island of Hawaii [Smith and Grubisić, 1993]. The similarity of the wake structure between Kauai and Oahu verifies previous theoretical and numerical modeling studies [Smolarkiewicz and Rotunno, 1989; Bauer et al., 2000].

[14] The surface thermal forcing of Oahu and Kauai affects the circulation and thermal fields in the wake. During the day, westerly sea breezes develop in the wake close to the shore. The sea breeze is $400 \mathrm{~m}$ deep lee of Kauai and Oahu. Our soundings lee of Kauai reveal the vertical development of land breezes during night. The land breezes advect cool air from the island, forming a surface cool layer capped by an inversion. This cool layer is $200 \mathrm{~m}$ after midnight and develops to $500 \mathrm{~m}$ deep before dawn. Soundings in the wake are about $2 \mathrm{~K}$ warmer in the afternoon than at night, and this daytime warming extends from the surface to $1500 \mathrm{~m}$ in height.
[15] Independent observations suggest that the island diurnal effects extend far from the coast. Cloud lines develop in the afternoon trailing the islands of Kauai and Oahu for $100 \mathrm{~km}$ downstream. These trail clouds dissipate during night. Based on numerical simulations for 2005 summer, Y. Yang et al. (submitted manuscript, 2007) propose a thermal advection hypothesis: the downstream advection from the island warms the wake during the day, and the diurnal warming lowers surface pressure in the wake, causing surface convergence in favor of cloud formation. From the cruise observations, there is some evidence for enhanced diurnal temperature variations in the wake. The daytime observations lee of Kauai, however, does not show enhanced warming in the wake, possibly because the sampling along the cruise track is not optimal. Our cruise took place in December when the diurnal cycle in solar radiation is at the annual minimum. Summer cruises are desirable in the future to observe stronger diurnal cycles in the wake and the cross-stream variations in diurnal temperature changes in particular.

[16] Ship-board measurements show that the SST diurnal cycle is stronger in than outside the wake, 0.16 vs. $0.08 \mathrm{~K}$ for the day (1200-1800) minus night (0000-0600 HST) difference. The enhanced SST diurnal cycle in the wake is likely due to weak winds and/or the thermal advection from the island. Weak winds suppress vertical mixing, in favor of strong daytime warming. The trail clouds appear to be a negative feedback; the enhanced SST warming in the wake helps trail cloud formation during the day, which reduces solar radiation.

[17] Acknowledgments. The survey was conducted as a student cruise, and we wish to thank B. Taylor and K. Hamilton for the initiative and support. We wish to thank the anonymous reviewers for their comments, and D. Henderson for editing the text. We wish to thank the students and faculty participating in the cruise, the captain and crew of R/V Kilo Moana, who made this study possible. This study is supported by the NOAA PRIDE program, NASA, and JAMSTEC. IPRC/SOEST publication $7248 / 497$.

\section{References}

Bauer, M. H., G. J. Mary, I. Vergeiner, and H. Pichler (2000), Strongly nonlinear flow over and around a three-dimensional mountain as a function of the horizontal aspect ratio, J. Atmos. Sci., 57, 3971-3991.

Burk, S. D., T. Haack, L. T. Rogers, and L. J. Wagner (2003), Island wake dynamics and wake influence on the evaporation duct and radar propagation, J. Appl. Meteorol., 42, 349-367.

Calil, P. H. R., K. J. Richards, Y. Jia, and R. R. Bidigare (2007), Eddy activity in the lee of the Hawaiian Islands, Deep Sea Res., Part II, in press

Lane, T. P., R. D. Sharman, R. G. Frehlich, and J. M. Brown (2006), Numerical simulation of the wake of Kauai, J. Appl. Meteorol. Climatol., $45,1313-1331$

Nickerson, E. C., and M. A. Dias (1981), On the existence of atmospheric vortices downwind of Hawaii during the HAMEC project, J. Appl. Meteorol., 20, 868-873.

Nguyen, H. (2006), Numerical simulations of airflow and weather during the summer over the island of Oahu, M. S. thesis, 159 pp., Univ. of Hawaii at Manoa, Honolulu.

Porter, J. N., D. Stevens, K. Roe, S. Kono, D. Kress, and E. Lau (2007), Wind environment in the lee of Kauai Island during trade-wind conditions: Weather setting for the Helios Mishap, Boundary Layer Meteorol., 123, 463-480.

Sasaki, H., and M. Nonaka (2006), Far-reaching Hawaiian Lee Countercurrent driven by wind-stress curl induced by warm SST band along the current, Geophys. Res. Lett., 33, L13602, doi:10.1029/2006GL026540.

Smith, R. B. (1989), Hydrostatic airflow over mountains, in Advances in Geophysics, vol. 31, pp. 1-41, Academic Press, San Diego, Calif.

Smith, R. B., and V. Grubišić (1993), Aerial observation of Hawaii’s wake, J. Atmos. Sci., 50, 3728-3750. 
Smolarkiewicz, P. K., and R. Rotunno (1989), Low Froude number flow past three-dimensional obstacles. Part I: Baroclinically generated lee vortices, J. Atmos. Sci. 46, 1154-1164.

Xie, S.-P., W. T. Liu, Q. Liu, and M. Nonaka (2001), Far-reaching effects of the Hawaiian Islands on the Pacific Ocean atmosphere, Science, 292, 2057-2060.
Yang, Y., and Y.-L. Chen (2003), Circulations and rainfall on the leeside of the island of Hawaii during HaRP, Mon. Weather Rev., 131, 2525-2542.

J. Ma and S.-P. Xie, Department of Meteorology, School of Ocean and Earth Science and Technology, University of Hawaii at Manoa, 2525 Correa Road, HIG 352, Honolulu, HI 96822, USA. (xie@hawaii.edu)

Y. Yang, National Institute of Water and Atmosphere, 301 Evans Bay Parade, Hataitai, Wellington, New Zealand. (y.yang@niwa.co.nz) 